\title{
Implementation of the Presidential Youth Fitness Program 實践總統青少年體迶能計劃
}

\author{
Joe DEUTSCH
}

North Dakota State University, U.S.A.

\begin{abstract}
The Presidential Youth Fitness Program (PYFP) is a product of Shape American, the governing body of physical education in the United States of America. The significance of the PYFP is that it is an all-encompassing program that seeks to not only assess fitness but too promote health-related fitness and lifestyles. The criterion referenced zones students seek to achieve, allows teachers to reward the process, as well as the results. Implementation of all appropriate tests is covered, as well as interpreting the results and recognizing students for their accomplishments.
\end{abstract}

Key words: physical education, assessment, fitness testing, health-related fitness, physical fitness

\section{摘 要 \\ 美國總統青少年體適能推廣計劃, 是監控體育科的指標之一。透過有效的測驗準則, 可讓教師容易推廣。}

\section{Introduction}

The mission of Shape America (formerly known as American Association of Health, Physical Education, Recreation, \& Dance) is to advance professional practice with in physical education, physical activity, dance, and sport. When specifically speaking about physical education in the primary school system, they implement a program called Presidential Youth Fitness Program (PYFP). The mission of the program is to help American youth to be active and fit. While the originally implemented in 1966, President Youth Fitness Testing, simply assessed their fitness levels and reported them in norm referenced format, it did nothing to encourage change or to teach appropriate eating and activity behaviors. The PYFP does include assessment, although it is criterion referenced, and the program takes the emphasis off of the test and focuses on the promotion and process if health-related fitness. There are three main components that drive PYFP, training of teachers on proper implantation of appropriate fitness tests, how to assess the results, as well as how to access free material for parents and children to improve the results. The information contained in here is based off of the Physical Education Resource Guide to the
Presidential Youth Fitness Program and can be obtained at www.pyfp.org/doc/teacher-guide.pdf.

\section{Fitness Tests}

The test items are all encompassing to ensure accurate results as well as to assess all parts and components of the body. Below are the areas to test and implementation procedures for each test.

\section{Aerobic Capacity}

When assessing aerobic capacity, a mile run was traditionally used in the past. The Progressive Aerobic Capacity Endurance Run (PACER) is a more ageappropriate alternative to the mile. There are two versions of the test, where students either travel 15or 20 meters every time they hear a beep. The background music is motivational and the students cannot travel the next leg of the race until they hear another beep. The process forces students to wait and thus they begin to learn to use the maximum amount of time between trips to conserve as much energy as possible and attain more lines. Every minute the beeps get closer together and it becomes increasingly more difficult for students to 
make it to the next line and eventually do not and the test is completed. The students score will fall into one of the three zones based on potential risks for future health problems. The zones include Healthy Fitness Zone (low rick for future health problems), Needs Improvement (in between low and high risk) and Needs Improvement - High Risk (high risk for future health problems). The students' main objectives should be to attain the Healthy Fitness Zone through behavior changes. While the result is their assessment, the process should be rewarded by the teacher regardless of the physical result. Some children do not attain results at the same rate as others.

\section{Body Composition}

As our Nation has become increasingly more litigious, we no longer recommend our students perform skinfold testing in the public schools. While Body Mass Index (BMI) does not do an accurate job of taking into account muscle, it is not our job as physical educators to be providing accurate body composition. Our job is to identify potential issues to parents and recommend they see a medical doctor to be properly assessed.

BMI $=(($ weight in pounds $/$ (height in inches) $\mathrm{x}$ (height in inches) ) $\times 703$ or

$\mathrm{BMI}=$ weight in kilograms $/$ (height in meters) $\mathrm{x}$ (height in meters)

\section{Abdominal Strength}

The use of curl-up strips and a cadence allows teachers to get an accurate read of a student's abdominal strength while not injuring their backs in the process. Students lay on their backs in the traditional sit-up position and a sit-up strip is placed just below the bend in the knee. When the arms are laid at the side, the finger tips should just touch the beginning of the strip. When the cadence says "up", the students will squeeze their stomach muscles together as hard as they can, thus sliding the finger tips the width of the strip and hold them there until the cadence says "down". Students continue at this pace until they can no longer maintain the pace. Students receive one opportunity to get back on pace when they miss the cadence and after they miss again, their test is complete.

\section{Upper Body Strength}

The use of 90 degree push-ups to a cadence is a highly effective way to assess upper body strength in children. As opposed to allowing the child to control their own pace, the cadence forces the student to hold the down position much longer than they are accustomed to. Similar to the abdominal strength test, the 90 degree push-up test is done as a group to a cadence. If a student misses the cadence, they again have an opportunity to get back on track and after they miss again, their test is completed. This method allows to watch an entire class of participants at once, because the must be up or down according to the cadence.

\section{Lower Body Flexibility}

The back-saver sit and reach is the most accurate way to assess lower body flexibility. The objective of the test is to reach out as far as a student can on both the left and the right sides of the body. The backsaver version of the traditional sit and reach, performs the test on one side at a time. By testing one leg at a time, hyperextension of both knees can be avoided. The assessment requires a 12 inch high box and a yard stick. The number of inches a student can reach is recorded on each side, with a maximum score of 12 inches.

\section{Upper Body Flexibility}

The shoulder stretch test is performed with both the right and left arms. The test is quite simple. When assessing the right shoulder, the student reaches over their head and down between their shoulder blades and then with the left arm they reach across and up and try to touch their middle finger tips together. If the student is flexible enough, the fingers will touch. Then the test is performed with the opposite arms. The student is assessed yes they can or no they cannot, individually with both shoulders.

\section{Summary of Fitness Testing Results}

As stated on page 54: In interpreting performance on physical fitness assessments, it is most important to remember the following: 
- The principal fitness experience should always be fun and enjoyable.

- Physical fitness testing should not become a competitive sport.

- The performance of one student should not be compared to that of another student.

- The primary reason for testing is to provide the student with personal information that may be used in planning a personal fitness program.

- The performance level on fitness tests should not be used as a basis for grading.

\section{Recognition and Conclusion}

The PYFP strongly recommends the use of processbased recognitions. In order to keep students motivated to life a healthy and active lifestyle, it is important to reward the process, especially when some students do not see the same strides in their physical results. Through the use of the spread sheet provided on the website, student results can be maintained not only from the beginning of the year to the end, but throughout many years. This allows students to set goals based on the areas they want to improve in. When they reach their goal for a specific area, they may change focus and set goals for another area. By focusing on rewarding the process more than the product, the focus of fitness testing is changing in America from simply testing to test, to testing to set goals and benchmarks for improvement. The Presidential Youth Fitness Program is the future of physical education where we promote life-long physically active learners.

\section{References}

Presidents youth fitness program teachers guide. (2014). Retrieved September 2, 2014, from http://www.pyfp. org/doc/teacher-guide.pdf

\section{Correspondence}

Joe Deutsch, Ph.D.

Associate Professor,

North Dakota State University,

United States of America

P.O. Box 6050, Department 2620, Fargo,

ND 58108-6050

Email: joe.deutsch@ndsu.edu 